\title{
The Traditional Marketing Advertising Impact Global Warming
}

\author{
Tawfik Saeed Zeki \\ College of Business Admiration, American University in the Emirates
}

\begin{abstract}
There were many features of the use of paper advertisements in all areas of newspapers, magazines and books even in retail stores even Internet ads were more appealing to advertisers. You can simply reach your goal local audience. We see a lot of advertisers who distribute brochures to people some interest and keep the brochures they think might need it and others not interested they try to throwing it anywhere some goes in dash bins and the rest goes in the main road. Eventually thus presents the environment pollution. In this paper we will be exposed to the importance of information technology and style of reducing the vulnerability of the environment and the impact global warming thus the human risks.
\end{abstract}

Keywords: Traditional marketing, advertising global warming

\section{Introduction}

The relationship between Information Technology and Marketing

Today, many marketers wish to employ modern marketing to draw more customers rather than using old-style marketing. Because of fast growth in technology, modern digital marketing has more chance to attract customers and progress company's sales and profits.Technologies, such as the Internet, mobile phones, social media, and (CRM) which is customer relationship management systems significantly affect the technique companies communicate with prospective clients. Most of business professionals and consumers are using their own computers and phones to search information and communicate with other businesses.

When many sources of information are available, it would be much easier for customers to satisfy their needs based on a competitive price and quality.Marketing technology is not just about making existing processes additionaleffective. It's the interface by which marketing gets and traces the digital world figure (1).

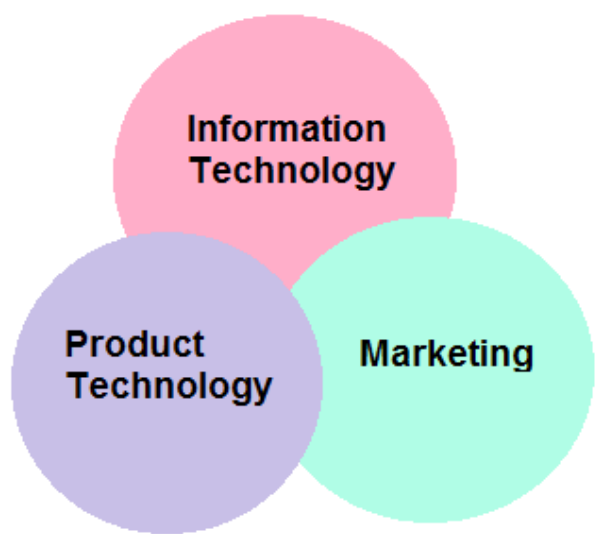

Figure (1) the most intersection in the world

Technology has impacted the field of marketing significantly, along with virtually every other discipline in business. In marketing, the impacts of technology are diverse. Organizations are tasked with managing more marketing options than ever before, and consumers are more integrated with marketing information than they have been in the past.

\section{Impacts on the Organization}

From the organizational viewpoint, technology has impacted the capability to collect and organize marketing data, the organization can use to reach consumers, and the process of developing different types and layouts of advertising possessions. Organizations have more data, more marketing formats, and more available places to communicate with consumers (i.e. Newspaper, Magazine, posters,etc.).

When considering the influence of technology as a marketer, what's greatest important is maintaining a full scope of the applicable options and channels that can be utilized to communicate with potential and currentconsumers? 


\section{Impacts on the Environment}

To produce paper takes twice the energy used to produce a plastic bag. Everything takes energy to produce. In the case of paper, it also involves cutting down trees. Deforestation is one of the main environmental problems we're facing in these times. $42 \%$ of all global wood harvest is used to make paper. Is it really worth it to cut down our life saving trees for this product?

With the improvement in technology and the advent of the printing press and the mechanical harvesting of wood, disposable paper became more affordable for the average consumer. This resulted in a drastic increase in consumption and of course, waste which all contributed to Paper Pollution. It is estimated that $40 \%$ of the waste in the U.S. is paper [6].

Here are ten scary facts about paper waste and its related costs that are sure to spook you into more earthfriendly behavior.

1. The average American office worker uses 10,000 sheets of copy paper every year.[1]

2. The average American citizen uses about the equivalent of one 100-foot-tall Douglas fir tree in paper and wood products every year.[1]

3. The average American office worker uses about 500 disposable cups every year (paper and plastic).[1]

4. Paper makes up $28 \%$ of municipal solid waste (MSW), more than anything else Americans throw away.[2]

5. The pulp and paper industry uses more water to produce one ton of product than any other industry.[3]

6. Paper accounts for up to 71.6 million tons of waste per year.[4]

7. The average American office makes 19 copies of each paper document.[5]

8. Offices also lose one out of 20 paper documents.[5]

9. These offices then spend up to $\$ 120$ searching for every misfiled paper document.[5]

From the consumer side, marketing has become increasingly integrated into everyday life. From Facebook advertising to Google paid search results, the average consumer has an increasingly personalized and data-driven exposure to 'relevant' ad materials. This is all not to mention the various devices and distribution formats, spanning from computer browsers to mobile to tablet distribution.

Thanks to the enormous amount of information available, primarily from social networks and browsing behavior, consumers are also being impacted from a privacy point of view. From what we watch on TV to who our friends are to what career paths we are on, all of this information is being utilized thanks to social networks and browser cookies.

Ad blindness is another interesting outcome of the modern technology-driven marketing. As consumers are exposed to more and more sponsored content, the ability to ignore marketing materials (particularly online) has grown quite high. As consumers are accosted with more and more content, they have evolved the capacity to consciously and subconsciously ignore sponsored ad content.

\section{Traditional Marketing}

There are many facets of traditional marketing and examples might include tangible items such as business cards, print ads in newspapers or magazines. It can also include posters, billboards and brochures.

Because of its longevity, people are accustomed to traditional marketing. Finding ads in magazines and newspapers, or reading billboards are still familiar activities and people still do them all the time. Most of the time, traditional marketing is reaching only a local audience even though it is not limited to one figure (2).

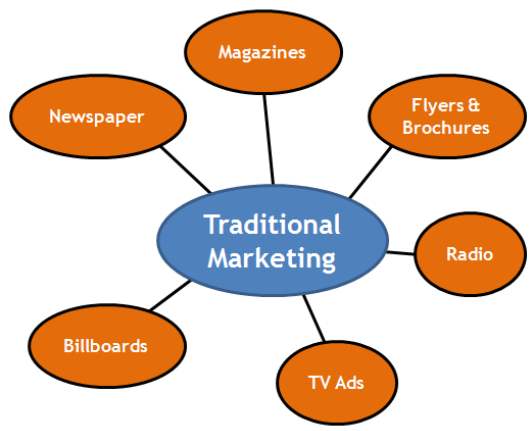

Figure (2) Traditional Marketing

One of the primary disadvantages of traditional marketing is that the results are not easily measured, and in many cases cannot be measured at all. In most cases, traditional marketing is also more costly than digital marketing. And perhaps the biggest disadvantage today is that traditional marketing is static which means there 
is no way to interact with the audience. It's more like you are throwing information in front of people and hoping that they decide to take action.

\section{Outdoor Advertising Media}

When personsconsider of Outdoor Advertising, they typically think of the colorful billboards beside our streets and roads. Included in the "outdoor" organization, however, are benches, posters, signs and transportation advertising (the advertising on buses, subways, taxicabs and trains)They are all share like advertising rules and methods.Outdoor advertising reaches its people as an element of the environment. Different newspaper, radio or TV, it doesn't have to be invited into the home. And it doesn't provide entertainment to sustain its audience.

\section{Some Outdoor Advantages}

Since it is in the public domain, Outdoor Advertising assuredly reaches its audience. People are exposed to it whether they like it or not. In this sense, outdoor advertising truly has a "captured audience."

Particular places can be acquired for certain purposes. A billboard located a block in front of your business can direct people to your showroom. Or you can reach rural areas efficiently by placing a billboard in each small town.Outdoor advertising is brilliantassistant to other kinds of advertising you are doing. In fact, it is most active when joined with other media.

\section{Some Outdoor Disadvantages}

Outdoor advertising is a quickmedium. At best, it only draws 2-3 seconds of a reader's time.

Messages must be brief to fit in that 2-3 second time frame. Ninety-five percent of the time, either the message or the audience is in motion. The kind of the way you have to buy outdoor advertising (typically a three month commitment) is not a very short, week-long campaign. When you buy outdoor advertising, remember that place is all. High traffic areas are ideal. A billboard in an unwanted area will do you little good. Retain your message brief (use only five to seven words) and make it creatively attractive to attract readership. Few words, large illustrations (or photos), bold colors and simple backgrounds will make the greatest effective outdoor advertising messages.

But the poorer things people ignore it, how long the advertising people keep it and what they do it after that. The answer quite clear all these advertise papers goes to dishpan as a result thus climate will be adversely affected.

\section{IT Model Fighting Climate Change}

Climate change is actualand particularlythe result of human actions. Naturally, the silver lining to this dark cloud is that if climate change is the consequence of human action, then there exists the possibility of a human solution. Here are some technique that technology may help us fight climate change.

\section{Mobile technology}

Mobile devices are universally, and charging these devices places a line on electrical frames. But mobile devices are also greatly helpful - they put the world at your fingertips and connect people everywhere.

Positively, modern mobile processors, like Intel Core i7-6700K, are becoming progressively energy efficient, and even offer face like Quick Charge to reduce their load on electrical nets. Together, these developments could significantly reduce carbon footprints universal.

\section{Mapping technology}

From GPS technology for individual use to advanced satellite mapping for the commercial regality, today's mapping technologies offer us with a treasure of information. Not only do our cellular phonehave access to mapping information that would have been top top-secret 20 years past, but satellites are also providing unique information on climate change, ocean temperature, wind and further, all of which helps governments and private administrationssimilar institute policies designed to relieve environmental footprints.

\section{Technology is the Solutions}

As information technology continues to become cheaper, every object that can conceivably provide valuable information will eventually be equipped with information technology. The massive amounts of data produced by these objects will not be processed by traditional software written and tested by humans. Instead, other information technology will analyze it and look for patterns.From this standpoint, in order to mitigate the negative impact on the climate, in order to reduce dependence on paper-based advertising. It proposed in this paper change the way you look and feel of the announcements to the use of modern technologies in the IT world. 
In most studies is the study of philosophy study marketing on the following points [7].

1. Analyse the Market

2. Analyse Competition

3. Research Distribution Channel

4. Define Your Market

5. Analyse Financial

6. Review \& revise

7. Understand your customers

We can noticed in the figure(3)

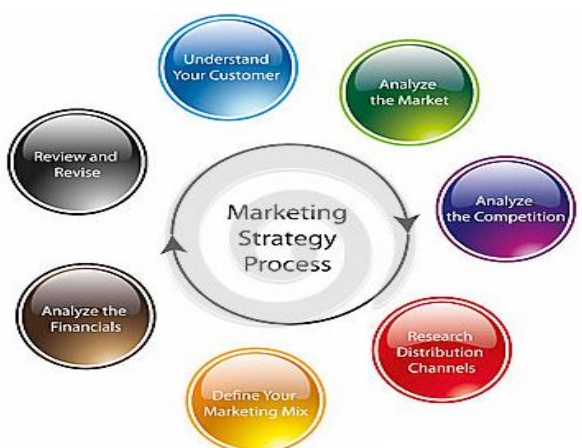

Figure (3) Marketing Strategy Process

Strategy through the marketing cycle note the absence of style and display technology the product to the customer. This is an essential point in any setting strategy for shopping and having great importance to the study of a product display by digital advertising instead of resorting to the use of paper advertisements.

This study added to the model addressing shopping strategy to the process of using digital advertising and linking from both review and revisethe advertising display before starting. On the other hand linked with the customer to understand the product marketer and thus strengthen customer opinion from the goods and the feedback. Which all illustrated in figure (4)

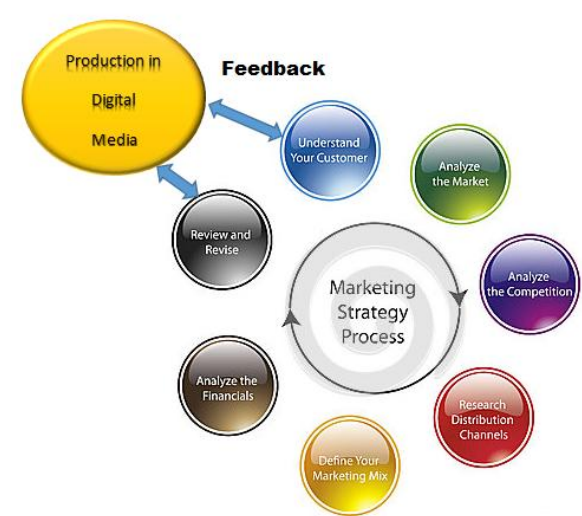

Figure (4) New Model for Marketing Strategy Process

Man-made problems require man-made solutions. From mobile processors that are more energy efficient and quicker to charge to electric and technology allows us to reduce our carbon footprint and lessen our environmental impact. All that's required for success is worldwide adoption Figure (5).

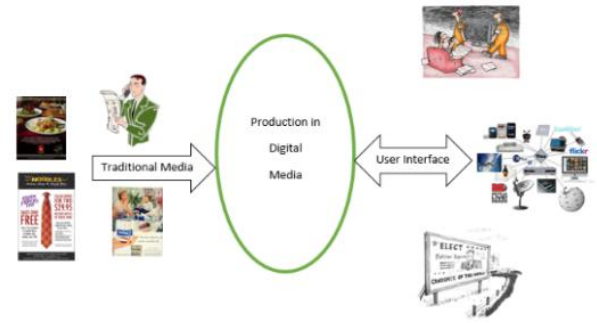

Figure (5) Media Production Processed 


\section{Conclusion}

I think, it is impossible to attain long term business success without leveraging the benefits of information technology in this digital age.Marketing and IT need to be better aligned and more collaborative. The company should determine the strategy and process first, and then find the right way to execute that fit the tool to the problem, not the problem to the tool.Identifying the ideal target market from the data, figuring out which channels this market tends to use and which products fill their needs is a strategic necessity in the modern technological era for organizational success.

\section{References}

[1]. http://www.cleanair.org/Waste/wasteFacts.html

[2]. http://www.epa.gov/solidwaste/conserve/materials/paper/index.htm

[3]. http://en.wikipedia.org/wiki/Paper_pollution

[4]. http://www.epa.gov/osw/wycd/catbook/what.htm

[5]. http://ecm.laserfiche.com/document-management/

[6]. http://www.theworldcounts.com/stories/Environmental_Impact_of_Paper_Production

[7]. https://it.dreamstime.com/fotografia-stock-libera-da-diritti-processo-di-strategia-di-marketing-image 25251765 